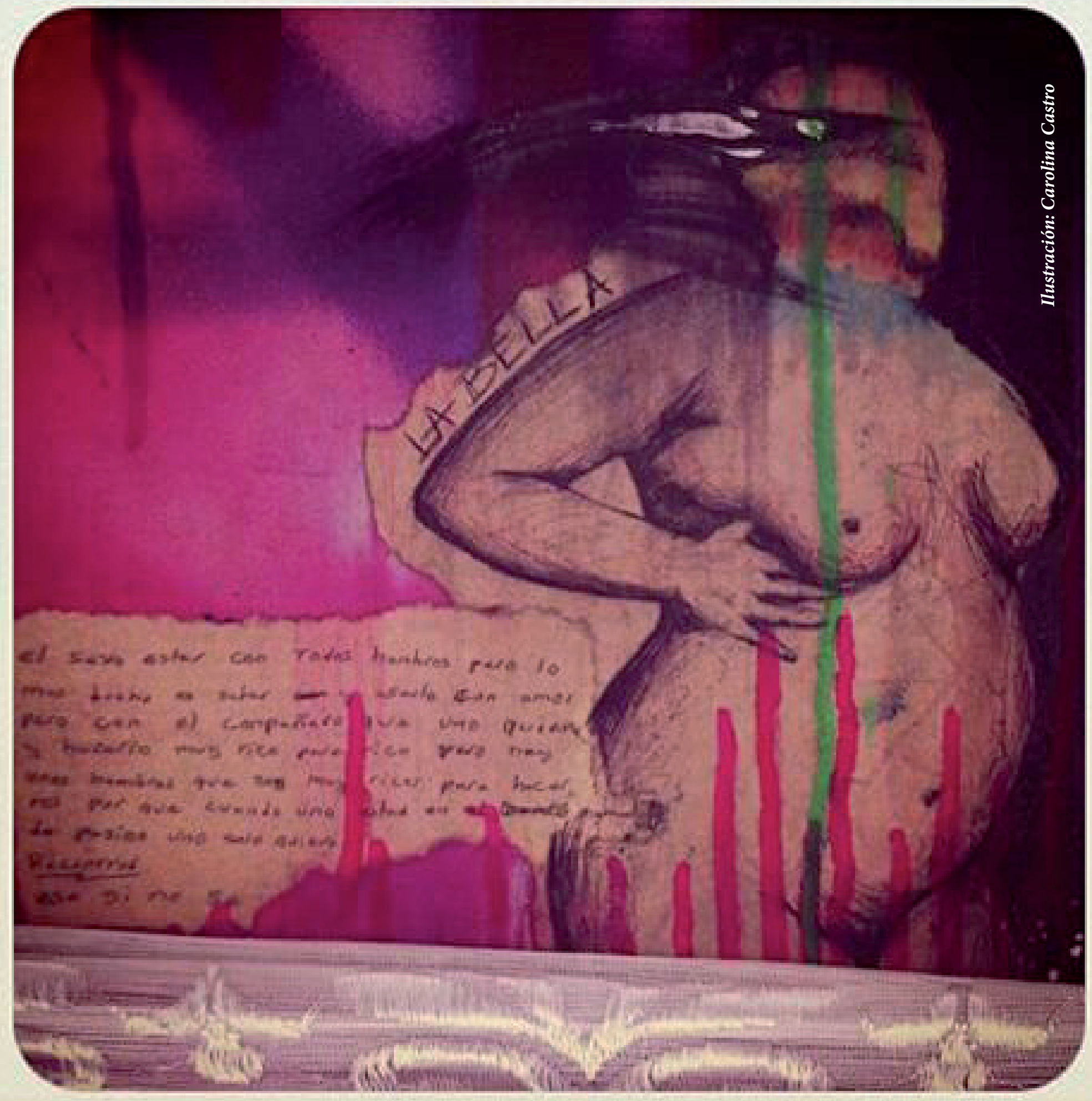




\title{
EDUCACIÓN SEXUAL CON PERSPECTIVA DE GÉNERO: REFLEXIONES ACERCA DE SU ENSEÑANZA EN BIOLOGÍA Y EDUCACIÓN PARA LA SALUD
}

\section{Sexual education with a gender perspective: contributions for the teaching in Biology and Health Education}

\author{
Graciela Morgade ${ }^{1}$ \\ Paula Fainsod ${ }^{1}$ \\ Catalina González del Cerro ${ }^{1}$ \\ Marta Busca ${ }^{2}$
}

\begin{abstract}
Resumen
El artículo presenta resultados de un proyecto de investigación de la Universidad de Buenos Aires tendente a elaborar contenidos y enfoques curriculares relativos a la construcción del cuerpo sexuado en distintas asignaturas. En este escrito nos proponemos problematizar la transversalización de la perspectiva de género en Biología y en Educación para la Salud, dos asignaturas tradicionalmente vinculadas a la educación sexual. Se trata de un diseño metodológico de investigación-acción participativa, en el que se describen y analizan propuestas de enseñanza elaboradas conjuntamente con la docente a cargo de ambas materias, en una escuela secundaria de la ciudad de Buenos Aires. Como principales resultados encontramos que la transversalización de la perspectiva de género involucra una vigilancia epistemológica sobre el androcentrismo en las fuentes del currículum, así como también una revisión de las principales premisas del modelo bio-médico hegemónico que configuran "núcleos duros” resistentes en ambas asignaturas. En la experiencia descrita encontramos que los aportes de la pedagogía feminista resultan elementos potentes para la enseñanza de la educación sexual desde el abordaje propuesto.
\end{abstract}

Palabras claves: Educación sexual, androcentrismo, modelo biomédico, transversalización del género, pedagogía feminista

\section{Abstract}

This article summarizes the results of a research project from the University of Buenos Aires, which aims to elaborate contents and curricular approaches related to the construction of embodied sex in different subjects. In this paper we will try to problematize the gender perspective in Biology and Health Education, two of the subjects traditionally linked to sexual education. This is participativeaction research, in which teaching proposals are described and elaborated together with the teacher in charge of both subjects in a public High School in the City of Buenos Aires. As part of the main results, we have found that the gender perspective involves an epistemological surveillance on the androcentrism in the sources of the curriculum, as well as a revision of the principal premises of the hegemonic medical model. In the described experience we found that the contributions of feminist pedagogy are powerful tools for teaching sex education with the proposed approach.

Key words: Sexual education, androcentrism, biomedical model, mainstreaming of gender, feminist pedagogy.

1 Morgade Graciela, Fainsod Paula y González del Cerro catalina-Instituto de Investigaciones en Ciencias de la Educación-Facultad de Filosofía y Letras-UBA; Correo contacto: paulafainsod@yahoo.com.ar

2 Busca Marta-Colegio Na4 Nicolás Avellaneda. 


\section{Introducción}

Desde ya hace algunos años, un importante caudal de investigaciones y trabajos del campo socioeducativo advierte acerca de diferentes procesos y mecanismos a través de los cuales las instituciones escolares participan en la producción de los cuerpos sexuados. Los estudios de la sociología y pedagogía crítica junto a los aportes de los feminismos, los estudios de género y las producciones de los movimientos socio-sexuales confluyen en una serie de reflexiones que muestran cómo desde sus orígenes los sistemas educativos - junto a otras instituciones- producen y reproducen un status quo en torno a las relaciones de género y las sexualidades.

Contra las argumentaciones que insisten en cuestionar la legitimidad de la incorporación sistemática de la educación sexual, resulta necesario explicitar que en la escuela, desde que es escuela, y en todos sus rincones, circulan contenidos vinculados a la sexualidad. De formas más o menos sutiles, en lo dicho y en lo silenciado, las instituciones escolares imponen una normatividad respecto de la sexualidad y de los cuerpos sexuados, en el que se exige una coherencia y continuidad entre genitalidad, identidad de género y orientación sexo-afectiva de las personas.

En lo que refiere a la enseñanza de la educación sexual a través del currículum explícito, de formas más o menos formalizadas, han prevalecido $-\mathrm{y}$ configurado un enfoque "tradicional" hegemónico- dos grandes modelos: biologicista o biomédico, por una parte, y moralizante por otra (Morgade, 2011). La forma habitual de entrada a la escuela del modelo biomédico ha sido su amparo en los postulados positivistas que lo instituyen como autoridad indiscutida validada científicamente para establecer qué enseñar, cuándo enseñar y quién debe enseñar educación sexual. La neutralidad y objetividad científica se erigen desde este discurso como garantías de su veracidad y certeza. Verdad que se explica por la evidencia empírica, en cuanto conocimiento racional de la realidad, de lo que la realidad es. De esta manera, el modelo biomédico adquiere autoridad para decir "la verdad de los cuerpos", "la verdad de la sexualidad" y lo válido a enseñar en las escuelas respecto de este campo.

Desde este modelo, prevalece una mirada de la sexualidad como un hecho natural. Se comprende así a lo natural como lo biológico, lo dado, lo que determina quien uno/a es sexualmente y su experiencia sexual. Desde este modelo, abordar la sexualidad en las escuelas es hablar de genitalidad y de reproducción, entendidos como procesos naturales, universales, estables. El eje se coloca en las amenazas de las enfermedades o "los efectos" no deseados de la sexualidad, lo cual evidencia el componente normativo/valorativo invisibilizado tras la neutralidad científica. A partir de allí, consolida un discurso patologizante de la sexualidad reducida a una situación de riesgo o peligro. Este discurso presenta tres rasgos distintivos: se centra en la prevención como una cuestión del "cuerpo humano"; como un corpus que se enseña desde un saber experto y que está destinado principalmente a mujeres y heterosexuales (Morgade, 2011).

De la mano de los aportes del campo de los feminismos y de los estudios de género a partir de los años 80 , más fuertemente, se hacen presentes otros análisis que tensionan las argumentaciones sostenidas por el enfoque tradicional y aportan elementos para repensar el abordaje de la educación sexual en las escuelas. Estos análisis introducen dos dimensiones que resultan centrales. Por un lado, expresan que la identidad de género es una construcción social y no un rasgo que deriva de la anatomía (leída recurrentemente como biología-natural). En tal sentido, sus aportes identificarán los modos de socialización diferencial y desigual entre los sexos-géneros que conllevan particularizaciones y fragilizaciones en las experiencias de sexualidad. Desde una perspectiva relacional, sostiene que las diferencias deben leerse en términos de jerarquías socialmente construidas en el contexto del capitalismo patriarcal; se aporta una mirada que denuncia cómo las jerarquías de género interactúan con otras como las de clase, edad, color de piel, nacionalidad.

Por otro lado, la perspectiva de género habilita un debate profundo que visibiliza la persistente presencia de discursos androcéntricos (centrados en andros, del griego 'hombre') y heteronormativos (estableciendo que la heterosexualidad es lo "normal" y otras identidades pasan a ser "anormales") que reinan en las instituciones sociales, interpelando - entre otras - a la ciencia, a la medicina, a la escuela misma. Así, se tensionan estos sesgos en las aulas y pasillos, en todos los niveles y en todas las disciplinas y espacios curriculares; entre ellos en la educación sexual.

En ese contexto de disputa académica y política es que se sanciona en la Argentina en el año 2006 la Ley 26.150 de Educación Sexual Integral (ESI). Esta normativa, que aunque con resistencias se encuentra vigente, establece que en todas las escuelas del país, y en todos los niveles y modalidades, debe dictarse educación sexual. Junto a la sanción de la Ley Nacional -y como una de sus consecuencias-a partir del 2008 se crea el Programa Nacional de ESI y el Consejo Federal de Educación establece lineamientos curriculares para todos los niveles de enseñanza. Estos tres dispositivos establecen entre algunas de sus prescripciones que la educación sexual debe enseñarse desde un enfoque integral. El artículo primero de la normativa nacional establece una definición de educación 
sexual integral como la "que articula aspectos biológicos, psicológicos, sociales, afectivos y éticos".

Y también, en relación a esta caracterización integral, los lineamientos curriculares establecen la presencia de una perspectiva de género ${ }^{1} \mathrm{y}$ de derechos humanos: la perspectiva crítica de género como indagación sistemática de las relaciones de poder/saber vinculadas con la construcción de los cuerpos sexuados subyacentes en todas las dimensiones de la práctica educativa; la perspectiva de derechos humanos como el parámetro de "justicia" de anclaje para la crítica y la práctica política.

Dicho enfoque representa una fuerte ruptura en relación a la educación sexual tradicional biomédica, y es el legado más importante que imprimió la participación de las organizaciones feministas en su discusión pública previa y también en su elaboración. A su vez, estos dispositivos establecen que su enseñanza debe darse de modo transversal sin reducir su abordaje a un espacio de taller dictado por especialistas externos, o restringirlo a las áreas de Biología y Educación para la Salud. En ese sentido, la sanción de la Ley 26.150 resulta un hito altamente significativo ya que habilita que sean los/las propios/as docentes de distintas asignaturas quienes - contando con espacios de capacitación-aborden los contenidos.

Investigaciones previas elaboradas por este mismo equipo dan cuenta de que si bien en las escuelas se presenta una preocupación institucional por la "educación sexual integral", y aun con los avances políticos de la Ley, las experiencias escolares de abordaje de temas de sexualidad muchas veces suelen vincularse a intereses personales de lxs docentes de las distintas instancias curriculares, más que a decisiones institucionales. También vemos que a nivel individual, la Ley permitió una "desclandestinización" (Díaz Villa, 2012) del trabajo pedagógico por parte de docentes que ya venían asumiendo la tarea en sus disciplinas, pero que el marco legal habilitó su visibilización y legitimó sus preocupaciones en torno a una educación sexual crítica.

1 La palabra género no aparece incluida en la ley y los lineamientos curriculares de alcance nacional, como resultado de las negociaciones con otros sectores religiosos durante su elaboración. Lo más cercano al enfoque que podemos encontrar en su formulación del objetivo: "Procurar igualdad de trato y oportunidades para varones y mujeres". La Ley Nacional esi, los lineamientos curriculares que le siguieron, y particularmente las líneas de acción elaboradas durante los siete años del Programa Nacional esi dan cuenta de la incorporación de la perspectiva de género y de derechos humanos, y la reconocen como eje central de esta política educativa. Vale destacar que en la Ley esi 2110 de la ciudad autónoma de Buenos Aires sí aparece explicitada como uno de los principios del artículo 4.
En este contexto, el equipo de investigación, en el cual se inscribe este trabajo, ${ }^{2}$ decidió acompañar la defensa y efectivización de la Ley 26.150. A partir del trabajo compartido con docentes de escuelas secundarias se generó el proyecto de investigación-acción: "Educación sexuada y currículum: debates epistemológicos y metodológicos desde la perspectiva de género". El proyecto se propuso continuar una línea de investigación desarrollada por el equipo, elaborando contenidos y enfoques curriculares relativos a la construcción del cuerpo sexuado, conjuntamente con equipos docentes de escuelas medias de la Ciudad de Buenos Aires. Entre los objetivos del proyecto, se menciona el acompañamiento de experiencias de desarrollo curricular con enfoque de género en cuatro áreas curriculares del secundario (Formación ética y ciudadana, Historia, Biología/Educación para la Salud y Lengua); la reconstrucción del contenido de cada uno de los espacios curriculares seleccionados transversalizando la perspectiva de género y sexualidades; la reconstrucción de las visiones/representaciones de lxs docentes, tutorxs y equipos directivos respecto de los modos juveniles de habitar el cuerpo sexuado antes y después de las experiencias.

Este escrito espera aportar algunas reflexiones en torno a la enseñanza de la educación sexual en dos espacios curriculares específicos: Biología y Educación para la Salud. Espacios que históricamente han tenido mayor legitimidad para enseñar sobre lo que, desde una mirada biomédica y preventiva, define la educación sexual: principalmente, la explicación sobre tipos y usos de métodos de prevención de embarazos e infecciones de transmisión genital. A partir de allí surge como interrogante: ¿cómo abordar la educación sexual con perspectiva de género en estas asignaturas por fuera del modelo biomédico? A través del corpus presentado se busca describir y analizar la implementación de dos propuestas de aula para la escuela secundaria; propuestas que intentan problematizar, desde la perspectiva de género y sexualidades, algunos de los núcleos centrales de cada uno de los espacios curriculares e intenta, así, desafiar la lógica hegemónica.

\section{Sobre los debates metodológicos y epistemológicos}

El artículo que presentamos forma parte de una investigación-acción participativa enmarcada en los estudios culturales y de género, orientada a desvelar las relaciones sociales en las que se enmarcan las experiencias educativas de construcción del cuerpo sexuado. El enfoque

2 Dirigido por la Dra. Graciela Morgade con sede en el Instituto de Investigaciones en Ciencias de la Educación de la Facultad de Filosofía y Letras- uba. Facultad de Filosofía y Letras- uba. 
metodológico de esta investigación y estudio pretende producir conocimientos de situaciones y procesos en profundidad a partir de una indagación participativa donde el proceso sea mediado por un equipo formado conformado por investigadrxs universitarixs este equipo de investigación y "docentes-investigadorxs que ejerzan en la escuela secundaria. Se nutre de la tradición de la investigación-acción participativa (IAP). Esta es una práctica que concibe la investigación y la participación como momentos de un mismo proceso de construcción de conocimiento y se asienta en el paradigma de la teoría social crítica. Por ello, busca que el "objeto" de estudio devenga sujeto participante en esa construcción de conocimiento colectivo sobre su entorno cotidiano (Sirvent, Lomagno y Llosa, 2009, p. 3).

El proyecto reconoce dos grandes antecedentes teórico-metodológicos: la "grounded theory" (Glasery Strauss, 1971) y la etnografía en su versión interpretativista (Rockwell, 2007). Entendemos a la escuela como portadora de un papel central en la construcción de sentidos hegemónicos, también concebimos a los sujetos sociales como potenciales productores del cambio. Asimismo, compartimos con esas tradiciones la hipótesis de que la reflexividad que los "agentes" tengan de los condicionantes de su vida social, y que los convierte en "sujetos", es una condición necesaria, aunque no suficiente, para la transformación social. El enfoque procura en este punto poner en tensión esa experiencia con procesos sociales, históricos y culturales más amplios que de alguna manera configuran y limitan esa experiencia (Elias, 1990).

La selección de casos se ha realizado por muestreo intencional; se buscaron docentes que trabajasen en escuelas secundarias de gestión estatal de la ciudad de Buenos Aires en las áreas establecidas por el proyecto, y con algún tipo de acercamiento a la temática de la educación sexual integral (ya sea por haber realizado cursos de formación específica, o bien por tratarse de militantes activistas en el movimiento social de mujeres o sociosexuales).

La escuela secundaria finalmente seleccionada está ubicada en el barrio de Palermo, en Capital Federal. Se trabajó con un curso de $4 .^{\circ}$ año, en el primer cuatrimestre del 2012 en el caso de Biología. En el caso de Educación para la Salud, las actividades se desarrollaron en un curso de 5. ${ }^{\circ}$ año en los primeros meses. La titular de ambas asignaturas, "MB" es profesora de biología con una trayectoria como docente del área de casi 30 años. En esta escuela trabaja hace más de 20 años. A lo largo de 9 años se desempeñó como referente escolar del Programa de retención escolar de alumnas embarazadas, alumnas madres y alumnos padres, y actualmente es referente de la consultoría o "salita" de salud sexual en la misma escuela, proyecto que creó junto a otro colega de la institución.
El dispositivo metodológico de investigación se desarrolló en dos momentos. En una primera etapa, llevamos adelante una serie de instancias participativas de programación y planificación de una propuesta didáctica para cada espacio curricular. En concreto, se trató de sucesivos encuentros entre el equipo de investigación y la docente-investigadora. Allí se discutió la programación de las asignaturas, sus potencialidades y limitaciones para trabajar con una perspectiva de género, las transformaciones y adaptaciones que fueron sufriendo los programas y actividades. En esta instancia se relevaron diferentes textos utilizados en el aula (muchos escritos por la propia docente), propuestas de actividades previas y documentos curriculares, consignas de evaluaciones. Luego nos dispusimos a construir conjuntamente las respectivas planificaciones. Dada la trayectoria de la docente, cuenta con una cantidad significativa de recursos y actividades que fueron tomadas, alguna sin modificación, y otras con adaptaciones o agregados surgidos de estos encuentros de planificación conjunta.

En un segundo momento, se llevó adelante la implementación de las propuestas didácticas por parte de la docente. Estas fueron acompañadas por una serie de observaciones etnográficas de las clases planificadas en el primer momento, y el relevamiento de las producciones realizadas en el marco de esas clases. Finalmente, se realizaron encuentros de análisis y evaluación del proceso entre el equipo y la docente-investigadora. Como uno de los productos del proceso se realizó un trabajo conjunto de escritura sobre la experiencia de investigación desarrollada.

\section{La perspectiva de género en la investigación científica y en su enseñanza}

No es casual que la metodología elegida para esta investigación apunte a la participación activa y productiva de la docente, que forma parte de la población involucrada en la política educativa a nivel institucional. La modalidad de investigación-acción participativa cuestiona los métodos tradicionales que pretenden perfilar una autoridad epistémica sustentada en la idea de "objetividad" y "neutralidad" que traen lxs científicos sociales externos a la institución o distanciadxs de la problemática a investigar.

La "neutralidad" de la ciencia ha sido cuestionada por décadas. Sin embargo, es a partir de los años setenta que la sociología del conocimiento elabora una rigurosa lectura política del cientificismo. Se cuestiona entonces la pertenencia de lxos científicxos a una clase social y raza dominante, y su actitud conservadora en defensa de los privilegios de la elite científica y social; a su vez, el campo de la historia de la ciencia saca a la luz el carácter proce- 
sual y relacional de las teorías científicas, y pone en duda sus pretensiones de universalidad. En este marco, y ya desde su punto de vista particular, el movimiento social de mujeres dirá que el "campo científico" es uno de los ámbitos sociales de la reproducción del sistema sexo-género que establece como punto de referencia al varón heterosexual. Acompañando los desarrollos de la teoría crítica, la epistemología de inspiración feminista denuncia tempranamente el carácter sesgado de las nociones de "verdad", "objetividad", "neutralidad", "valores" o "poder" (Pacheco Ladrón de Guevara, 2010) en la ciencia tradicional positivista. Esta reproducción se expone en dos dimensiones del vínculo entre género y ciencia: por un lado, en la indagación por ver "quiénes" hacen ciencia, y, por el otro lado, "cómo y qué" se investiga. Con relación al primer punto, Diana Maffía (2007, p. 2) señala el efecto doble que tiene la expulsión del campo científico de las mujeres y de muchas masculinidades subalternizadas, en tanto busca "impedir nuestra participación en las comunidades epistémicas que construyen y legitiman el conocimiento, y expulsar las cualidades consideradas 'femeninas' de tal construcción y legitimación, e incluso considerarlas como obstáculos". Respecto del segundo punto, y vinculado al anterior, el qué y cómo se investiga se erigen como indiscutiblemente racionales para la adquisición de una visión universal y objetiva del mundo, expresa el punto de vista que las feministas llamamos "androcéntrico" que crea, legitima y justifica la capacidad naturalmente racional de unos y la falta de condiciones indispensables del resto de los sujetos que, en cuanto portadorxs de condiciones a las que les restan cualquier valor epistémico, quedan justificadamente excluidos de este campo.

Vemos así que el ejercicio reflexivo sobre qué sujetos conformaron tradicionalmente la comunidad científica permite poner en evidencia que lo que tal comunidad produce-el conocimiento científico- está sesgado por las experiencias subjetivas de aquellos sujetos. Que las mujeres hayamos sido históricamente "objeto" de la ciencia, pero no así sujetos protagonistas de ella, permite comprender el persistente androcentrismo en el campo científico y en su proceso de construcción de teorías. Con "androcentrismo" nos referimos a los valores dominantes del andros, esto es, sujeto varón adulto y propietario. Los sujetos que no están en condiciones de elaborar conocimiento válido son quienes no responden a esta clasificación (mujeres, niñxs y esclavos) y, por consiguiente, a lxs que se les atribuye capacidades de menor valor epistémico: subjetividad, sensibilidad, singularidad, narratividad. Estos se oponen (y siguiendo el mismo orden) a la objetividad, la racionalidad, la universalidad, y la abstracción, elementos centrales del pensamiento científico dominante.
Así, lo que las feministas reclaman no es complementar las perspectivas masculinas y femeninas o sustituirlas (por ejemplo, lo singular sobre lo universal, o lo sensible sobre lo racional); se aspira a una reconfiguración de las propias categorías masculino/femenino. En este proceso, uno de los desafíos mayores es desarmar el propio esquema dicotómico, binario, que sostiene el pensamiento científico tradicional y que se corresponde con la construcción binómica de los géneros: cultura/naturaleza, mente/cuerpo, fuerte/frágil, público/privado, y más. Se propone, por el contrario, una transformación de las categorías mismas para desarrollar una ciencia que discuta y visibilice que el binarismo es una forma externa de "ordenar" elementos diversos, una forma que impone una norma. En esta línea es que se produjo la investigación que se presenta, desde la cual señalaremos en este apartado tres recaudos epistemológicos.

Un primer recaudo fue atender a la reflexividad feminista acerca de los supuestos básicos de la investigación científica: definimos la "objetividad" como construcción intersubjetiva. La compleja interrelación de sujetos, prácticas, métodos y técnicas es lo que le brinda autoridad a nuestro trabajo, que se triangulan teniendo en cuenta que todxs los actores de la comunidad escolar saben, actúan y resignifican las políticas de educación sexual.

Un segundo eje "que vigilar" fue el vínculo entre lxs sujetos con posiciones institucionales diversas y jerárquicamente vinculadas. Las investigaciones sobre las prácticas pedagógicas continúan caracterizadas por una división social en la cual la función propia de la universidad es crear conocimiento, mientras que a las escuelas no les quedaría más que "llevar a la práctica". Vale destacar que una dificultad metodológica que encontramos en el transcurso del trabajo de campo fueron las condiciones laborales propias de la docencia. Lxs docentes de nivel secundario tienen escaso tiempo para dedicar horas de trabajo a la investigación por su fuerte sobrecarga de horas de clase en los establecimientos, ello implicó un esfuerzo particular por parte de la docente.

En tercer lugar, la investigación expresa de modo explícito un posicionamiento político. Asume no solo la dimensión descriptiva del género (como una construcción social y no un rasgo que deriva de la anatomía), sino también la dimensión crítica que alude a la denuncia sistemática de las relaciones patriarcales y heteronormativas de poder.

Proponemos, entonces, reflexionar mediante la propia práctica de investigación sobre los siguientes axiomas que Elizabeth Anderson (2010) postula para comenzar a delimitar una epistemología feminista: se conoce desde un cuerpo; la primera persona (el conocimiento de sí) es 
una fuente válida en la construcción de conocimiento científico; las personas se representan el mundo a partir de la mediación de las emociones y los sentimientos y por lo tanto también conocen desde esa integralidad; la relación entre sujetos incide en el conocimiento que llega a construirse; las diferentes habilidades lingüísticas, las diferentes creencias y los diferentes estilos de conocimiento inciden en las formas de interpretación (citado en Morgade, 2013, p. 5).

Ahora bien, ¿qué sucede con la ciencia en cuanto objeto de enseñanza, en particular en las asignaturas que exploramos aquí? Así como el feminismo denuncia que el conocimiento científico aparece sesgado por las condiciones propias de su producción, también concibe el "conocimiento escolar" como una expresión de las formas tradicionales (androcéntricas) de construcción y división del saber.

La teoría del currículum afirma que el conocimiento escolar es una construcción formalizada diferente de la que los campos mismos de las ciencias académicas han deparado: los campos son escenarios de lucha, con reglas de inclusión y exclusión orientadas por fuentes de prestigio y de financiamiento mucho menos maleables que el currículum explícito escolar.

El "qué" y "cómo" se investiga es una decisión adoptada en ámbitos académicos: lo que se investiga en los institutos de las facultades, que se difunde en revistas nacionales e internacionales, que se ramifica en especialidades y que es permanentemente debatido por personas que constituyen la "comunidad científica". Qué se enseña de lo que se investiga es una decisión que toman los equipos profesionales técnicos de las áreas de política curricular central y distingue en secuencia y gradualidad según niveles. Por último, qué se enseña en cada escuela y/o aula es otro nivel de decisión, en el cual los miedos, las expectativas y los saberes docentes tienen una incidencia mayor. De alguna manera, entonces, los enfoques hegemónicos en cada disciplina se procesan en varios niveles de recontextualización (Bernstein, 1990). Es importante tener en cuanta esta recontextualización para entender los intereses y actores sociales que influyen en los circuitos de producción, financiamiento, transmisión, circulación y evaluación de los contenidos.

Nuestra perspectiva de análisis pone en tensión las decisiones tomadas en esos tres niveles de recontextualización curricular con el concepto de "justicia curricular" desarrollado por la pedagoga Connell (1997): primacía de los intereses de los menos favorecidos, participación y escolarización común para todos/as, la igualdad en la producción histórica. De la mano de estos postulados, la investigación se propuso generar procesos de construcción creativa y colectiva en búsqueda de propuestas pedagógico-curriculares tendientes a des-estabilizar las certezas, visibilizar las omisiones y re-inventar saberes en torno a los espacios curriculares trabajados desde el convencimiento del lugar insoslayable que ocupa la escuela en la construcción de nuevas posibilidades y horizontes en la construcción de los cuerpos sexuados (Morgade, 2011).

\section{Análisis de casos}

Hasta aquí se presentó de qué forma la enseñanza acerca de los cuerpos sexuados estuvo dominada por el modelo biomédico que sostiene su autoridad epistémica sobre "la verdad de los cuerpos" anclada en el orden natural y legitimado por su objetividad científica. En segundo lugar, se analizó la propuesta de la epistemología feminista que historiza y polítiza la autoridad epistémica de esta verdad y muestra el carácter sesgado del proceso de elaboración de teoría y de sus resultados, que conforman las fuentes del currículum escolar. Así, el androcentrismo en las fuentes del currículum vinculados a la enseñanza de los cuerpos sexuados puede verse plasmado en dos grandes ejes: el discurso esencialista que justifica, por un lado, el determinismo biológico en la materia Biología, y, por otro lado pero muy unido, la patologización de lo diferente en Educación para la Salud (eps).

Las ciencias naturales no son naturales, el currículum escolar tampoco. ¿Qué nos enseña la escuela sobre la naturaleza? ¿Qué enseña la biología sobre la ciencia? Aún resulta impensable plantear que los contenidos en Biología y EPS y las formas clasificatorias están orientadas por significaciones hegemónicas. Es decir, ordenamos la observación de la materia sensible según categorías socialmente disponibles.

El problema que nos ocupa aquí no es tanto esa persistente legitimidad del área, sino la pregunta sobre qué es lo que esta asignatura puede o debe reflexionar sobre sí misma: este lugar de autoridad epistemológica que suelen ocupar los/as docentes de ciencias naturales en la institución, en cuanto "especialistas", puede entenderse como un riesgo pero también como una oportunidad para llevar adelante los objetivos (quizás los más difíciles) que se propone la ESI con perspectiva de género.

Por un lado, se corre el riesgo de legitimar mitos o ubicar bajo lo "científicamente comprobado" clasificaciones arbitrarias acerca de "lo natural". Si se persiste en utilizar los términos naturaleza y normalidad como intercambiables a la hora de dictar un contenido de la materia, es probable que se confunda también diversidad con monstruosidad. Pero, por otro lado, la asignatura se presenta 
como una gran oportunidad para instalar nuevos espacios, preguntas o miradas sobre la sexualidad. Los/as docentes de esta área corren con ventaja al momento de proponer talleres, charlas, consultorías. Pero, sobre todo, su legitimidad se plantea como un desafío a la hora de problematizar las diferencias y así despatologizarlas. Si bien es cierto que hay cuerpos que tienen más padecimientos que otros y que se pueden alivianar por herramientas médicas, es fundamental el abordaje socioeconómico y cultural de aquellos.

Nos proponemos así ampliar la pregunta inicial: ¿cómo enseñar sobre los cuerpos sexuados en las asignaturas Biología y Educación para la Salud rompiendo con un paradigma esencialista y patologizante? ¿Cómo incluir una perspectiva (de género) que viene a cuestionar la autoridad de la propia ciencia en las asignaturas que enseñan ciencia y los saberes que de ella derivan?

La "pedagogía feminista" genera un aporte sustancial en la consolidación de una metodología que propiciaráa relaciones más igualitarias en términos de género al tiempo que produzca condiciones más justas de producción de saberes. Esta se preocupó, sobre todo:

\begin{abstract}
"En desarrollar formas de enseñanza que reflejasen los valores feministas: el dominio sobre los múltiples formas de conocimiento, incluyendo la experiencia como fuente válida, el ejercicio de la propia voz, la discusión de la autoridad y las fuentes de autorización, la centralidad de la posición antes que la esencialización de las relaciones de poder; en suma, un contrapunto de las prácticas pedagógicas tradicionales, que eran consideradas como expresión de valores masculinos y patriarcales" (Morgade; 2011,35).
\end{abstract}

Desde esta perspectiva es que se diseñaron una serie de propuestas curriculares y clases tendientes a desestabilizar lógicas imperantes en cada una de las asignaturas analizadas.

\section{Biología}

Tal como vimos en el apartado anterior, un punto central de la perspectiva crítica de género se refiere a la identificación de la ciencia en cuanto discurso que elabora las clasificaciones de la naturaleza de modo arbitrario. Aclarar

3 La pedagogía feminista se desarrolló fundamentalmente en la universidad, sobre todo en los entonces recientemente creados departamentos de "Estudios de la Mujer" y se centró sobre todo en cuestiones pedagógicas ligadas a la enseñanza universitaria de temas feministas y de género (Morgade, 2011,; p. 33). que lo que llamamos "mundo natural" no está esencialmente dividido en especies y subespecies sino que somos los humanos quienes ordenamos prolijamente nuestras percepciones para poder estudiarlas es el caso del pensamiento occidental y su ciencia positivista-- marca un punto de partida fundamental sobre el cual volver permanentemente. Existen algunos contenidos o unidades temáticas "clásicas" de los programas curriculares de Biología que la docente identifica como desafiantes pero a la vez facilitadores para habilitar la reflexión sobre los debates vistos hasta aquí.

Revisemos algunos ejemplos. La enseñanza de la historia de la investigación científica abre la posibilidad de abordar críticamente la ciencia, y permite desmitificar la imagen de "científico neutral", a la vez que permite problematizar el papel que jugaron las mujeres y las personas no heterosexuales en la producción científica. En la unidad "genética", es importante poder identificar los riesgos del determinismo genético binarista; determinismo muy instalado por la sociobiología y presente en los discursos hegemónicos sobre desigualdades de índole social. En relación con el racismo, por ejemplo, es sugerente aclarar que la categoría "raza humana" no tiene asidero en la genética u otros criterios que haya establecido la ciencia actual, pero si lo tuviese, la pregunta para guiar su enseñanza podría centrarse en la justificación o no de las prácticas injustas y desiguales entre humanxs. A su vez, en las descripciones de combinaciones genéticas posibles en la fecundación de dos gametos, también resulta sugerente estar atentos en los ejemplos dados a no dar por sentado la universalidad de vínculos afectivos y familiares heterosexuales. En la enseñanza de la reproducción humana, en particular sobre los métodos de cuidado de embarazos e infecciones disponibles, incluir una perspectiva de género requiere problematizar las expectativas y autonomías desiguales entre varones y mujeres al momento de negociar su uso y decidir cuándo, dónde, con quién, para qué y cómo utilizar un método de protección. La variación en las formas de reproducción animal también resultan sumamente enriquecedoras para abordar la complejidad y dinamismo de lo no humano. La extrema variedad de modos de reproducción y de mutaciones entre machos y hembras presentes en las distintas especies representan una gran oportunidad para ahondar en un paradigma que no conceptualice al mundo natural como ordenado y fijo, sino, por el contrario, como diverso y en constante movimiento.

Para esta investigación elegimos analizar un tema específico del área de biología que no suele estar vinculado a la educación sexual integral desde una perspectiva de género y mucho menos suele estar abordada desde una perspectiva de género: la enseñanza de la evolución humana. El recorte empírico elegido fue el dictado de la 
unidad didáctica desarrollada en 18 clases de un módulo (con 80 minutos cada uno), y la clase destinada a la evaluación (presencial, individual, escrita). El objetivo de dicha unidad fue que lxs estudiantes pudieran profundizar en los conocimientos en torno al proceso de hominización y clasificación de la especie humana. Para ello se trabajó con los aportes de la paleoantropología sobre los cambios anatómicos y fisiológicos adquiridos por las especies antecesoras al actual Homo Sapiens, así como también las diversas formas que fueron tomando los supuestos disciplinares a lo largo de la historia de dicha rama científica. La secuencia de actividades combinó diferentes recursos didácticos (imágenes, notas periodísticas, película documental, redes sociales) y alternó discusiones en pequeños grupos con clases plenarias, tareas individuales para hacer en casa y producciones grupales en clase. De esta manera, en un proceso espiralado, se volvió muchas veces sobre las mismas ideas fuertes, complejizando la mirada cada vez, integrando contenidos e ideas previas, anticipando relaciones con otras materias u otros temas.

La evolución no es un tema más. Por el contario, el enfoque evolutivo es un eje estructurador en la enseñanza del conocimiento biológico actual y recorre gran parte de la asignatura desde $1^{\mathrm{a}}$ hasta $5^{\circ}$ año. Tal como se escribe en "Darwin y la evolución. Aportes para la enseñanza en nivel medio" (Shnek 2009), el enfoque evolutivo es el marco teórico de referencia en la producción de conocimientos elaborados en las más diversas especialidades de la biología en sus diferentes niveles de complejidad. Si bien existen discusiones y cuestionamientos al neodarwinismo planteados desde fines de la década de 1960, la gran mayoría de los biólogos contemporáneos coinciden con que nada tiene sentido en biología si no es a la luz de la evolución.

A continuación se analizan algunas escenas del trabajo en el aula que permiten identificar algunos puntos o ejes centrales en el abordaje de una perspectiva crítica de género en esta unidad temática. Este modo de esquematizar la "aplicación" de una perspectiva a partir de ejes nos permite por un lado, identificar aspectos de un abordaje que posiblemente esté presente en las prácticas diarias, pero de forma naturalizada, sin vincularlas con un posicionamiento político o pedagógico determinado. Por otro lado, facilita la reflexión sobre las múltiples formas de "incorporar el género" sin necesidad de introducir nuevos temas.

\section{Sobre las múltiples desigualdades}

Se comenzó la unidad temática preguntando al grupo sobre los pensamientos que se les aparecían generalmente frente a las palabras "evolución humana". Rápi- damente surgió, por unanimidad, la siguiente la representación:

\section{Escena 1:}

"Profesora: ¿Recuerdan cuáles son las cinco críticas a la representación de la evolución humana?

Alumna: No hay mujeres. No hay niños.

Alumno: El primer "hombre" que aparece es blanco

Alumno: Hubo no solo una especie al mismo tiempo

Alumna: No nos paramos de a poco, era bípedo desde el principio, no como los últimos

Profesora: ¡Falta una sola!... iQue no descendemos del mono actual!

Varixs: Aaaahhhh.

La estrategia didáctica de traer esta pregunta que se realizó al principio de la cursada, y que luego se retomó en varias clases, sirve ahora de integración, para finalmente utilizarse como consigna de evaluación. Se optó por partir de una concepción previa de lxs alumnxs, posiblemente naturalizada, para luego contextualizarla en ciertas condiciones de producción que le fueron dando sentido hasta hoy. Por un lado, la deconstrucción de una visión que parecía consolidada en su imaginario les permite vivenciar el hecho de poder discutir una verdad instaurada. Es preciso comenzar por problematizar estas experiencias previas con el tema para luego pensar alternativas. La profesora arremetió contra la misma porque es la imagen más difundida y para muchxs representa la idea de una ciencia moderna y racional que supera al creacionismo. ¿Por qué, si sabemos que el primer homínido, fue negro seguimos trabajando con una imagen que no lo muestra? Unx no debería dejar de ver que induce a errores, y que esos errores no son inocentes. En distintos momentos de la unidad se mostró el contraste entre esta imagen y el árbol filogenético coincidente con el registro fósil.

Este análisis da cuenta de la existencia de no una, sino varias formas de desigualdades que atraviesan la construcción social del conocimiento. En este caso, un conocimiento sesgado por una cultura androcéntrica o machista pero también racista y eurocentrista. Incluso, existen otras imágenes en las que el último hombre aparece vestido, cubriendo todo su cuerpo (es habitual que se asocie la desnudez de algunas partes del cuerpo como signo de "atraso") con ropajes que dan cuenta de una vida urbana 
y burguesa. De esta forma se visibiliza el lugar central que ocupa el hombre blanco adulto saludable (y propietario) en el ideario de humanidad. Por contraposición, las mujeres, lxs niñxs y ancianxs, y el resto de las culturas no europeas que habitan el planeta aparecen relegadas en un segundo plano, así como los modos de vida de las clases marginalizadas y campesinas

\section{Sobre los modos de reconstruir el pasado}

En una de las clases se proyectó un largometraje ${ }^{4}$

\section{Escena 2:}

[Durante la clase posterior a la proyección, se abre el debate sobre los sesgos de género]

Alumno: “...otro ejemplo de esto de "ver con los ojos de hoy”, es cuando [en la película] insinúa el origen de la prostitución, cuando intercambia el colmillo... ¡Y no tiene nada que ver!"

Aquí el alumno hace referencia a una escena en la que un macho joven vuelve de la cacería con el colmillo que le confiscó al líder. Al regreso comparte la comida con la hembra. Se plantea un intercambio del colmillo por favores sexuales de la hembra conseguidos regalándole el colmillo. Se puede ver con este comentario, el riesgo de justificar la mercantilización de los cuerpos de las mujeres desde aquellas épocas. A su vez, escenas de amor romántico e "histeriqueo", aparecen y justificando una visión monogámica y heteronormativa característica de una mirada occidental y relativamente reciente. Lo interesante del comentario del alumno es que a partir de señalar otros sesgos, pudo identificar un mensaje subyacente que naturaliza una conceptualización- - fácilmente reconocible en la época actual-- de mujer/hembra como objeto sexual susceptible de ser utilizado y negociado entre varones/machos.

\section{Sobre los modos de comparar a las especies}

En una de las clases, la docente introdujo algunas nociones sobre el giro copernicano y la teoría de la evolución planteada por Darwin en el proceso de descentrar a la especie humana y la posibilidad de ubicarla como una rama más en el árbol de la vida. Durante el debate, la docente retomó el árbol filogenético visto con la clasifi-

4 Se trata del documental ficcionado "Caminando con cavernícolas", producido por la BBC en el 2003. Es una miniserie de TV de 4 episodios, dirigida por Richard Dale cación de los homínidos y de los primates. Es en este contexto en el que aparece el siguiente intercambio:

\section{Escena 3:}

Profesora: "¿Se acuerdan que se comparó la conducta del ser humano con la del chimpancé para ver qué cosas son en común y, entonces por eso, qué es universal?

¿Pero se acuerdan que yo les pregunté qué pasaría si se los comparara con los bonobo? Si decimos que la pelea ya estaba en el Homo habilis, también podemos entender que no nos queda más que pelear porque somos violentos por naturaleza”.

Av: ¿Pero todas las especies se pelean?

M: No en todas las especies se resuelve por pelea ([...]) o entre especies [(...]) puede ser por sexo, por compartir. ¡Ellos inventaron el "hagan el amor y no la guerra”!

La mención reiterada de la existencia del bonobo (Pan paniscus), que es una de las dos especies que componen el género de los chimpancés, Pan (la otra especie del género es el chimpancé común) se distingue por: 1) la tendencia a que sus individuos anden erguidos en ocasiones, 2) su cultura "matriarcal" e igualitaria, y 3) el papel preponderante de la actividad sexual en su sociedad. Al relatar los comportamientos de estos primates, tan cercanos filogenéticamente a la especie humana como los chimpancés comunes, se mostró cómo se puede elegir con cuál comparar en función del comportamiento que se desee naturalizar y justificar como inherente a la "naturaleza humana", como por ejemplo, la violencia en la resolución de conflictos. La intención es deconstruir con loxs estudiantes la falaz conclusión: "sSi un comportamiento existe en chimpancés y en humanos, ese comportamiento debió estar en el antepasado común, ergo es " "natural". Aquí se ve cómo la elección de los puntos de comparación que utiliza la ciencia no es inocente, sino que está sesgada por las formas de concebir a la propia humanidad. ¿Qué hubiese pasado si se atribuía como "natural" el comportamiento de los bonobos?

\section{Sobre las nociones de evolución:}

Avanzada la unidad, una de las actividades propuestas fue la realización de perfiles de Facebook por parte de los estudiantes. La consigna fue simular ser un individuo de algunas de las especies estudiadas del árbol filogenético estudiados. De esta forma, se buscó relacionar las características y las adaptaciones de cada especie vistas en clase, y los posibles comportamientos, plasmados en 
los comentarios, las imágenes subidas y las relaciones de "amistad" con otras especies. Se dedicó una clase a proyectar las diferentes producciones en Facebook y a comentar grupalmente.

\section{Escena 3:}

[En la sala de proyecciones, llega el momento de analizar el perfil de uno de los grupos.: Debajo del nombre "Lucy" aparece como información adicional "soy necesaria”]

Profesora: Es claro que esto es para todas las especies. Y no es Lucy la necesaria, sino el conjunto. Traten de poner lo que los hace diferentes al resto, lo que los identifica. $^{5}$

Concebir los cambios anatómicos y fisiológicos que van adquiriendo loxs homínidoxs como "necesarios" para llegar a ser lo que somos hoy es sostener una mirada Llamarckiana de la evolución, que consiste en explicar las adaptaciones como transmisión lineal de los cambios de una sola generación a las venideras, en pos de un destino: la forma de vida civilizada occidental urbana capitalista, etc. En el texto escrito por la profesora, "Falsas interpretaciones de la evolución biológica”, entregado a lxs alumnos, podemos ver que lo que se plantea es una anticipación a ejemplos como los recién expuestos. Citamos:

\begin{abstract}
"Como la evolución no tiene un sentido, ni una dirección, ni un diseño; no es posible predecir lo que ocurrirá a futuro. Esta afirmación está relacionada con una idea lamarquiana [sic], según la cual aquellos órganos que no se utilizan tienden a desaparecer. Discusión aparte es la utilidad de estas y otras estructuras, pero aún [sic] en el caso de que no la tuvieran lo que deja de ser útil solo deja de funcionar, no desaparece mientras tenga un carácter neutro y no implique una desventaja."
\end{abstract}

Si, por el contrario, entendemos evolución como permanente adaptación a un medio cambiante, no podemos comprender la diversidad como diferencias calificables en un orden estático, sino cómo variaciones. Este es un ejemplo de perspectiva de género que no remite a un machismo explíicito, si no que propone cuestionar la base misma del pensamiento patriarcal (y también racista). Dicha lógica justifica la jerarquización de formas de vida

5 Una de las estudiantes en su perfil escribió en su perfil, en vez de Homo habilis, "minu habilis". La fundamentación que ella dio fue que Homo hacía referencia a hombre, y para rescatar a las mujeres invisibilizadas escribió "minu" en referencia a "mina" (término lunfardo para mujer). que, según estén más o menos cercanas al ideal civilizatorio, o en términos clásicos, según sean más o menos primitivos, es decir, que fueron primeros en la línea evolutiva y que por caminar "más lento" quedaron detrás del Hhombre evolucionado. Desde esta perspectiva, la diferencia entre cuerpos e identidades, entre prácticas sexuales, no podría ser plausible de ser puesto en jerarquía.

Luego de recorrer estas breves escenas, volvamos a la crítica inicial sobre el esencialismo que fácilmente permea la enseñanza de la biología y el papel que juega aquí la teoría evolutiva. Ésta teoría o enfoque resulta por demás pertinente para cuestionar la propia idea de una naturaleza como estática y como determinante de las conductas sociales. Como venimos diciendo, dicho cuestionamiento debe ser un punto de partida para al abordaje de género que, como dijimos se posiciona en una mirada constructivista de los cuerpos sexuados, a la vez que cuestiona, sobre todo, los estudios y activismos de las últimas décadas, su sustrato naturaly, más aún, marca el carácter construido de la propia dicotomía naturaleza/cultura.

Retomando con lo dicho anteriormente, entonces, en la tradición occidental, la idea de lo natural fue asociado, a grandes rasgos, con lo normal, lo bueno, lo verdadero, lo sano, lo acabado, lo puro. En definitiva, con "lo perfecto" que siempre subyace a lo "accidental". Lo natural como aquello a lo que debemos obedecer en última instancia. La gran novedad que introdujo Darwin, en particular para la comunidad científica del siglo xIX, era la idea de que es necesario atender a "el origen" de las especies para poder estudiarlas. Más aún: debemos entender que las especies, y la propia naturaleza, son imperfectas. ${ }^{6}$. La teoría de Darwin permitió resignificar a la diferencia como aquello que hace inteligible a los seres, y a la diversidad como aquello gracias a lo cual sobreviven.

"El origen de las especies" dio, entonces, inicio a un pensamiento radicalmente opuesto: el mundo natural no es otra cosa que algo contingente y permanentemente

6 Dice Darwin "([...]) Nno debemos maravillarnos de que todas las disposiciones de la naturaleza no sean - hasta donde podemos juzgar - absolutamente perfectas, como en el caso del mismo ojo humano, ni de que algunas de ellas sean ajenas a nuestra idea de lo adecuado. No debemos asombrarnos de que el aguijón de la abeja, al ser utilizado contra un enemigo, ocasione la muerte de la propia abeja; de que se produzcan tan gran número de zánganos para un solo acto, y de que sean luego matados por sus hermanas estériles; ni del asombroso derroche de polen de nuestros abetos; ni del odio instintivo de la reina de las abejas hacia sus propias hijas fecundas; ni de que los icneumónidos se alimenten en el interior del cuerpo de las orugas vivas. Lo raro, dentro de la teoría de la selección natural, es que no se hayan descubierto más casos de falta absoluta de perfección." (citado en Schnek 2009,: p. 28). 
abierto. La naturaleza es diversidad y cambio. Y cambio no direccionadodeterminado. Es decir, que no existe un "propósito", ya que todo podría ser de otra manera, en oposición al paradigma hegemónico que plantea una tendencia natural a mejorar, hasta alcanzar el estadio más alto de progreso: la civilización. Coómo ya vimos en uno de los ejes, esta confianza en un "propósito" está relacionada con una idea lamarckquiana, ${ }^{7}$ según la cual, aquellos órganos que no se utilizan tienden a desaparecer. Discusión aparte es la utilidad de estas y otras estructuras, pero auún en el caso de que no la tuvieran, lo que deja de ser útil solo deja de funcionar, y no desaparece mientras tenga un carácter neutro y no implique una desventaja.

Esta tendencia a buscar el "propósito", muy arraigada en los/as propios estudiantes que aprendenr sobre hominización, es explicado por Schneck (2009), en su estudio sobre la historia de la enseñanza de la evolución en la Argentina. A finales de la década del 70 , de la mando de una tendencia internacional, la Dirección Nacional de Educación Media y Superior en Argentina

\begin{abstract}
"Promovió un enfoque predominantemente ecológico para la enseñanza de la biología que, si bien fue importante por su abordaje sistémico, tuvo un defecto sustancial: al poner el énfasis en las relaciones entre estructura y función de los seres vivos en sus entornos, sin referencia a los procesos evolutivos que conducen a la adaptación, reforzó un enfoque lamarckiano tanto en los libros de texto como en las actividades de aula." (Schneck, 2009, p. 17).
\end{abstract}

Los contenidos relacionados con las adaptaciones al ambiente aeroterrestre y acuático que predominaron en la enseñanza de los contenidos de Bbiología de esos años, son un ejemplo de ello.

Otra tensión que despertó la teoría sobre los orígenes de las especies, se vincula con la gran resistencia de la sociedad victoriana, que se vio obligada a poner en duda el mismísimo mito fundante de su religión cristiana - -el génesis--, y reemplazarlo por una menos atractiva parentela con los monos. En la actualidad, si bien la ciencia biológica prácticamente se funda sobre la teoría neodarwiniana de la evolución, a la vez que se sigue nutriendo de ricos debates teóricos, siguen existiendo ámbitos que ponen en cuestión cualquier pensamiento científico que no incluya la visión bíblica de la creación.

7 Lamarck sostenía erróneamente que los individuos tratan de adecuarse físicamente a los cambios del ambiente, por voluntad y para resolver problemas que le plantea el medio natural.
En este sentido, la teoría de la evolución y los estudios de género de las últimas décadas tienen en común una batalla declarada con los principales postulados de las grandes religiones porque, nuevamente, confluyen en una des-esencialización de la "naturaleza humana", ubicando el foco en el cambio y la diversidad. Pero la perspectiva de género también introduce la crítica a una matriz epistémica de la propia ciencia- - de la que la teoría evolutiva forma parte--, que no deja de estar permeada por un enorme sesgo androcéntrico, que refuerza el binarismo y la jerarquía de los cuerpos, tal como desarrollamos en los primeros apartados. Incorporar una perspectiva de género, en tcuanto dimensión construida y relacional, requiere un ejercicio permanente de evaluación de los cambios y las continuidades en los discursos científicos, religiosos --y también políticos--, así como también de sus sentidos fragmentados, contradictorios y siempre conflictivos. Poner en cuestión la mirada esencialista sobre los cuerpos y las conductas humanas, invita a repensar la propia asignatura y a reflexionar sobre las potencialidad que esta esconde para implementar una educación sexual integral con una perspectiva crítica.

\section{Educación para la Salud (EPS)}

En consonancia con lo planteado sobre el paradigma hegemónico en el abordaje de la biología en la escuela media, la perspectiva que prima en los diseños curriculares vinculados al espacio de Educación para la Salud también se encuentra permeado por el Mmodelo Mmédico Hhegemónico (MMH). De acuerdo a los aportes de Menéndez (1999), este modelo tendría los siguientes rasgos: biologicista, positivista, a-histórico, individualista, de orientación curativa, relación asimétrica médico-paciente. Este modelo se enlaza en los espacios de EPS a la perspectiva integral de la salud. Desde esta última, la salud se entiende como un estado de completo bienestar y equilibrio físico, psicológico y social. Aunque desde una mirada multicausal, que ejerce ruptura con la unicausalidad del biologicismo, en ella prevalecen ciertos binarismos opuestos: mente-cuerpo, naturaleza-cultura, individuo-sociedad, médico-paciente, salud-enfermedad. En las formas que toma el discurso hegemónico en este campo, uno de los polos de los binomios adquiere inequívocamente mayor jerarquía.

Bajo las banderas de la neutralidad científica del saber médico se impone un imperativo moral, un orden social y político. Respecto de los procesos de salud-enfermedad; la ciencia impondrá como naturalmente sano y moral cierto modo de vivir, de curar, de cuidar, de morir. Serán estos los valores de salud, higiene y moral. Este orden se mantiene, reproduce y produce a través de mecanismos

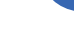

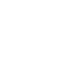


que los cultivan y protegen, evitando que entren en contacto con todo aquello que los tensiona/contamina.

La patologización de todo aquello "Diferente" que se aleja de la norma se convierte en uno de los mecanismos del control social y la reproducción del status quo. Así, en nombre de la buena salud, se intervinieron, violentaron, discriminaron, persiguieron, invisibilizaron $-\mathrm{-y}$ hasta mataron-- los cuerpos patologizados. El espacio de saber que posibilita clasificar, patologizar, disciplinary controlar los cuerpos sexuales se presenta bajo la sutileza de un discurso que en la "amnesia de la génesis" dice que no hace lo que hace.

La patologización asiste a dos recursos que colaboran en la cristalización de una miranda homogeneizante y polarizada de los procesos de salud-enfermedad: la a-historicidad y las argumentaciones individualizantes. Así, por ejemplo, la a-historicidad propone a ciertas experiencias como naturalmente normales y correctas y a otro conjunto de experiencias como diferencia deficitaria/desviada. El éxito o el fracaso, la normalidad o la anormalidad, la corrección o el desvío se presentan, a partir desde este mecanismo, como posiciones binarias de una jerarquía natural. Este binarismo no soólo lleva a invisibilizar las múltiples experiencias que se producen, sino que al naturalizar lo social refuerza la estigmatización hacia quienes ocupan un lugar inferiorizado en la jerarquía impuesta. Desde sus argumentaciones, el posicionamiento inferior es el resultado inequívoco de los errores o descuidos individuales, familiares o de ciertos grupos. En coincidencia con lo planteado, la lectura de los procesos de salud-enfermedad-atención, desde esta perspectiva, al des-historizar coloca en el individuo/en cada individuo la explicación y la responsabilidad de la experiencia que puede vivir, que le toca vivir.

A través de esta forma de leer las experiencias de salud-enfermedad-atención se produce y reproduce un discurso normalizador que tiene efectos materiales y simbólicos en la vida de los sujetos. En una búsqueda por consolidar una perspectiva crítica en los y las alumnos/as el primer bloque de contenidos que conforman la propuesta en EPS tendió a problematizar el concepto de salud. El énfasis estuvo puesto en visibilizar la dimensión social, política, económica de estos procesos y poner en tensión la normatividad que se impone desde el discurso médico hegemónico en torno a ellos. Como ejercicio contra-hegemónico, las escenas que se presentan en este apartado muestran dos decisiones pedagógico-metodológicas. Por un lado, a través de la propuesta didáctica se promovió la identificación de los condicionantes de las experiencias a fin de recomponer su historicidad; por otra parte, se identificó el lugar de las instituciones en la producción de las expe- riencias y las posibilidades de transformación, con lo que se desafiaronndo los discursos deterministas.

Como parte de los contenidos y estrategias que posibilitaráan la producción de una mirada centrada en la educación sexual desde una perspectiva de género en el abordaje de la Educación para la Salud se generó un proceso en dos tiempos.

En un primer momento, se analizó toda la propuesta programática anual de la materia y se trabajó en la transversalización de la perspectiva de género y sexualidades en ella. Este proceso permitió dar un salto cualitativo respecto de algunas miradas que tematizan el género y la sexualidad como un eje que se despliega soólo en el bloque de contenidos referidos a salud sexual y a salud reproductiva. El resultado de este primer paso fue la generación de una serie de bloques de contenidos vinculados entre sí y recorridos todos ellos por una mirada crítica, de género y sexualidades. Esta nueva versión de una propuesta programática, que generó más una lógica procesual que la de una sumatoria de contenidos, conllevó la necesidad de repensar la didáctica de la materia, las estrategias a desarrollar.

A partir de allí, una segunda instancia consistió en la planificación, desarrollo, observación y análisis de algunos de los bloques propuestos en la primera etapa. Posicionadas desde la pedagogía feminista, el desafío fue generar propuestas de aula tendientes a la problematización, a la puesta en juego de las experiencias y del saber de las experiencias como una dimensión más a tener en cuenta en el proceso de construcción de saberes.

En esta publicación se comparte el análisis de algunas escenas del primer bloque de contenidos. El análisis de las escenas permite ver el curríiculum en acción para, a partir de allí, visualizar las grietas, las invisibilizaciones reiteradas. Por este motivo, la presentación del corpus se organiza ex post facto a partir de la identificación de nudos significativos que señalan líneas que tensionan los núcleos centrales del espacio curricular.

En una búsqueda por consolidar una perspectiva crítica en los y las alumnos/as, el primer bloque de contenidos que conforman la propuesta en EPS tendió a problematizar el concepto de salud. El énfasis estuvo puesto en visibilizar la dimensión social, política, económica de estos procesos y poner en tensión la normatividad que se impone desde el discurso médico hegemónico en torno a ellos. Como ejercicio contra-hegemónico las escenas que se presentan en este apartado muestran dos decisiones pedagógico-metodológicas. Por un lado, a través de la propuesta didáctica se promovió la identificación de los condicionantes 
de las experiencias a fin de recomponer su historicidad; por otra parte, se identificó el lugar de las instituciones en la producción de las experiencias y las posibilidades de transformación, con lo que se desafiaronndo los discursos deterministas.

En unos primeros encuentros se problematizó el concepto de salud identificando algunas de las dimensiones que se conjugan en ella. Como producto de esa clase, que no se analiza en este trabajo, los y las alumnos/as armaron un cuadro en el cual se exponen las dimensiones/condicionantes de las experiencias. En una segunda clase, y tomando el cuadro como insumo, se invitó a analizar críticamente el caso de María Ovando, ${ }^{8}$ una mujer de sectores populares acusada por la desnutrición y la muerte de su hija.

Como insumos para el desarrollo de la actividad se utilizó una selección de artículos periodísticos en los que se expone el caso. A través del análisis crítico del caso, se construyó colectivamente el concepto de salud y sus condicionantes, destacando su dimensión histórica, social y política. Se visualizaron los condicionamientos de género presentes en la experiencia relatada, como así también los de clase, edad, residencia, entre otros. La reflexión acerca del caso potenció el análisis crítico de las propias experiencias en relación cona la salud, y pusoponiendo en discusión las perspectivas a-históricas y deterministas, como así también la perspectiva liberal que propone a la salud como un hecho individual y al mercantilismo que prima en los análisis hegemónicos respecto de las experiencias de salud-enfermedad-atención.

A continuación se comparten algunas escenas de las clases.

\section{Los condicionantes de la salud: de la unicausalidad a la multicausalidad, de lo individual a lo social}

A lo largo de la clase, en el momento de la puesta en común, se recorren las diferentes dimensiones que se conjugan en la experiencia de María. El proceso de identificación de los condicionantes colabora en que los y las alumnos/as detecten dos evidencias vinculadas entre sí. Por un lado, en el análisis comienzan a visualizar cómo en las

8 María vivía en un paraje forestal a la vera del río Paraná, en la provincia de Misiones. Analfabeta, pobre, víctima de violencia familiar, vivía con sus 12 hijos en absoluta situación de riesgo. En marzo de 2011 a raíz de un grave cuadro de desnutrición su hija Carolina de tres años muere en brazos de su madre, quien salió a pie por la ruta en busca de asistencia médica. Lejos de encontrar asistencia social, María se enfrentó a una dura política de criminalización por parte del Estado. experiencias de salud-enfermedad se conjugan una serie de desigualdades que conllevan una particularización del proceso de vulneración. Por otro lado, en el recorrido identifican el lugar de las instituciones. La dinámica que toma la clase permite la ruptura con los análisis unicausales e individualistas respecto de las experiencias de salud para asistir a una perspectiva multicausal, social e histórica. De este modo, cada vez queda más claro para todxs quienes están allí que la hija de María no murió sólo de desnutrición, sino que murió por una cadena de diversas situaciones injustas que producen este lamentable final.

\section{Escena 1:}

Profesora: ¿De qué trabajaba María durante su embarazo?

Am: ¿de picapedrera...??

Profesora: No es lo mismo que sea obrera de la construcción, o picapedrera o en un taller de costura... No es igual, para su salud, ¿no?? Picapedrera... ¿hasta cuándo trabajó??

Av: Trabajó hasta el final del embarazo.

Profesora: ¿Saben en qué consiste el trabajo de picapedrera??, así todos hablamos el mismo idioma... sacar las piedras de la caldera, sacarlas con un pico [(enfatiza como para dar cuenta de lo pesado del trabajo para una embarazada]).

La docente se encuentra atenta a poder problematizar cada una de las dimensiones analizadas, ver cómo en ellas se combinan los posicionamientos de clase, de edad, de sexo- género que conllevan a desarmar los nudos de las desigualdades, de las relaciones de poder que operan en las experiencias de salud-enfermedad. Así, insiste en poder analizar las condiciones de trabajo como una dimensión que se conjuga en la experiencia de María. Trabajar durante todo el embarazo, hasta su final, en una construcción, implica un trabajo de fuerza, de exposición a ciertos riesgos, a ciertas condiciones que inciden en la experiencia del embarazo, del parto, de la salud de la madre y del hijo/a. La pregunta por los modos en que se habitan las experiencias, por sus condiciones de producción, resultan altamente significativas en un contexto en el cual mantienen su hegemonía los discursos que, al invisibilizar las condiciones de producción de las experiencias, explican las desigualdades sociales - $-\mathrm{y}$ las de salud--- como resultado de déficit individuales y/o familiares $y / 0$ grupales. 


\section{Las particularizaciones y desigualdades de género: sus efectos en las formas de leer las experiencias de salud}

Ligado a lo anterior, la secuencia didáctica planificada enfatizó en los modos que operan las relaciones de género y las sexualidades en las dimensiones analizadas. De estae modo manera, durante el desarrollo de la clase se prestó especial atención a la identificación de las marcas de género en la historia de María O. Desde un principio las instituciones, entre ellas los medios y la justicia, soólo miraron a María para explicar laLA causa de la desnutrición y muerte de su hija. Sus errores, su ignorancia, su falta de instinto se presentan desde los medios como una cadena de argumentaciones que no hacen más que profundizar la invisibilización de los condicionantes históricos y culpabilizar a María por lo que le ocurrió.

En el discurso hegemónico prevalece una serie de procesos que colaboran en la inferiorización, discriminación y fragilización de ciertos grupos, en este caso, de las mujeres pobres. Estos procesos operan como naturalizaciones; conforman, en tal sentido, invisibles sociales:

"Un invisible social no es algo oculto o escondido, sino que -paradójicamente- se conforma de hechos, acontecimientos, procesos y dispositivos reproducidos en toda la extensión de la superficie social y subjetiva. Está ahí, pero no se lo ve o se lo considera como natural." (Fernández, 2012, p. 28).

Así, en el caso de los análisis de las experiencias de salud de las mujeres, y particularizando en las experiencias de las mujeres pobres, se produce violencia invisible cuando se desconocen los condicionamientos que operan en ellas.

En el discurso jurídico, mediático, médico se reitera un proceso de culpabilización a María por lo que le toca vivir. En tal sentido, la ignorancia, el desamor, el descuido, la desprotección de esa mujer son los que --desde el discurso hegemónico-- se presentan como elementos individuales que ponen en peligro a una hija/o. No soólo en estas argumentaciones se asiste a una a-historicidad, sino que se refuerza cierta normatividad respecto del ser mujer-ser madre que queda invisibilizada. Todos estos, componentes de un discurso moralizante.

En la siguiente secuencia se evidencia cómo a través de las preguntas que propone la docente se intenta desinvisibilizar las argumentaciones que producen violencia hacia las mujeres, en este caso, hacia María:
Escena 2:

Profesora: ¿Qué lugar tienen las mujeres en esta comunidad? Y acá necesito que me lo digan basándose en qué parte del relato me lo dicen. Cuando no lo procesan al marido, solo la procesan a ella, ¿qué lugar le estaría dando la sociedad? Vos lo habías dicho con mucha claridad.

¿Qué se espera de una mujer en una comunidad si la única procesada es ella?

Ao: Solo se espera que tenga hijos y entonces se la culpa porque dicen que no cumplió bien porque la tratan como una mala madre.

Profesora: Si solo se espera que tenga hijos, no cumplió bien con su mandato.

¿En qué otro lugar ven el lugar que tiene la mujer? Hay 203 frases más... que nos pueden dar unas pistas.

Am: aAcá dice... que fue víctima de la violencia física y verbal...

Am: qQue estaba trabajando al final de su embarazo.

Profesora: Todo esto que se espera que solo ella sea la responsable de los hijos, cuando se la procesa solo a ella y no a su marido, cuando vemos el maltrato físico en la familia y ahí estaría el tema del machismo... el tema que no se respetaban sus derechos al trabajar en la cantera hasta el final y no se consideró el riesgo ni de ella ni del niño que nació... y al final ¿qué dice? último párrafo.

Av: "El marido... estigmatizado... comienza ahora una lucha con $x x x$ y sus 2 nietos".

Profesora: ¿Qué es estigmatizado? ... ¿no tienen alguna idea?

Aa: El estigma, tiene que ver con un prejuicio.

Av: uUna marca.

Profesora: éÉl dice que es una marca el estigma, ¿quée marca tiene María?? ¿Cómo la consideraba la comunidad?

Av: Como se considera a una persona pobre, a una mujer pobre... Mala madre. 
La identificación de las dimensiones sociales de la salud, de los condicionamientos de género, constituyen también un recurso para desinvisibilizar las "estrategias bio-políticas" que producen procesos de fragilización y desigualación. De este modo, durante la clase se intentó ver cómo las instituciones, los mandatos que circulan en ellas tienen efectos materiales y subjetivos en la vida de las personas. En el caso de María, se desnudan la culpabilización y la estigmatización en tcuanto estrategias bio-políticas de normalización y disciplinamiento sobre el cuerpo de las mujeres pobres.

El discurso que circula por las instituciones, en ocasiones avalado por la ciencia, el discurso mediático, médico, escolar, no es neutral ni sin efectos. Ese discurso impone sentidos, modos de vivir los cuerpos, las sexualidades, la salud, "estableciendo parámetros de normatividad a partir de argumentaciones que se presentan como científicas y objetivas y que están atravesadas por ciertas condiciones de producción que se desconocen generando zonas de invisibilidad”. (Castorina, 2004,: p. 23).

sas argumentaciones configuran violencia simbólica, que tiene éxito justamente por las creencias que provoca. Des-hacer esas creencias es parte de la propuesta que se presenta aquí. La forma en la cual se leen las experiencias de salud, la identificación de sus múltiples dimensiones y condicionantes colaboran en la construcción de una mirada crítica respecto de estos procesos, habilita a pensarlos como procesos sociales, históricos y políticos de los cuales participan activamente diferentes instituciones, por ejemplo, las del campo médico.

\section{La salud como un hecho político, el lugar de los diferentes actores, las posibilidades de transformación}

En la clase que se expone en estos apartados se presentaron diferentes situaciones, diferentes reacciones de loxs alumnoxs. Silencios profundos, tristezas, enojos se fueron entretejiendo a lo largo del desarrollo de la clase. Resulta llamativo el intercambio con un alumno, E. Por supuesto, que las reacciones no se dan en el vacío. La clase alentaba en todo su conjunto a la búsqueda de las dimensiones que, a modo de cáscara de cebolla, se iban abriendo, dibujando y armando la historicidad de la experiencia de María. La docente incitaba a la participación de todoxs, con sus preguntas buscaba ir más allá de lo imaginado en tanto abría interrogantes que llevaban a loxs estudiantes a puntos de su propia experiencia, a preguntase por su propia mirada.
Escena 3:

Profesora: hHasta ahora lo que hicimos fue conocer la situación, tenemos los datos. Ahora empezamos a analizar. ¿Por qué se murió la niña?

Av: De desnutrición.,

Profesora: eEso sabemos, pero, ¿por qué se murió?,? ¿dice que tomaba la teta?, ¿por qué está desnutrida? relacionen con todo esto, ¿qué comía la mamá?...

Am: tTortilla.

Profesora: ¿pPor qué??

Av: pPorque tenía solo 170 pesos.

Av (E): eEs todo culpa del Estado, se llenan la boca y el eEstado... la que estaba procesada era María y no el eEstado, ellos son los culpables de la muerte.

Profesora: nNo te parece que desde la educación está bueno poder ver todos los cruces del problema, no son tan sencillos... aA ver, María... ¿cuando fue al banquillo de acusados podía tener esa claridad que tenés vos hoy??

IAv (E): La educación es importante... pero es un tema del eEstado.

Profesora: A ver, ¿qué estamos tratando de desarmar?... ¿cuáles son los determinantes?

eEn general, es considerado como un problema individual, lo que estamos tratando de ver es que no es un problema individual, que no es una responsabilidad de María... pero también viendo la complejidad de dimensiones, para no decir como mencionábamos al comienzo, es la pobreza, es el Estado... sino ver las distintas dimensiones que llevan a la muerte de su hija. Carolina se murió por todo esto... todo esto está determinando la salud. Para no caer en una charla de café, que está bueno, pero acá tratamos de abrir más preguntas y ver cómo se relacionan da lo mismo ser probre y ser María, que ser pobre y ser Juan. Da lo mismo vivir a orillas del Paraná y no tener acceso al hospital... ¿vos creés que hacemos eso??

$A v(E)$ : Yo intentaría hacer otra cosa, arrancar el problema de raíz, es una explotada, es pobre.

Profesora: eEstamos de acuerdo, pero también es necesario conocer la raíz a fondo. 
$A v(E)$ : yYo no quiero ofender a nadie.

Profesora: nNo, no creo, está bueno, estamos viendo cómo creés que hay que ver esto... te vi como enojado... Estás enojado con que esto suceda... y esto sucede todos los días... no solo a María.

¿pPor qué el caso de María salió a la luz?? eEso no lo dijo nadie...

Am: Porque la acompañaron las mujeres de la organización.

El enojo del estudiante y su irrupción en la clase resulta una situación inesperada. Como señala Britzman (1999), lejos de resultar una clase "guionada", la docente promueve la expresión de sus alumnoxs y en este juego se presentan situaciones que hasta también pueden llegar a resultar molestas. Sin embargo, pasado el malestar que genera enojo, pareciera que el enojo del estudiante posibilita ver dos cuestiones. Por un lado, resultaría hasta esperable que ante tanta injusticia puesta sobre la mesa, ante tanta violencia alguien/alguno pueda también violentarse, enojarse, irrumpir la clase denunciando esta situación. Por otro lado, también a partir del enojo de $\mathrm{E}$ se abre otro punto que también quiebra la lógica determinista e inevitable presente en las argumentaciones a-historicistas presentes en los discursos hegemónicos respecto de la Salud.

La visibilización de las diferentes dimensiones de la salud, de las instituciones implicadas en ella resulta un hecho político en sí, en cuanto se pone sobre la mesa el lugar no-neutral de las instituciones y cómo ellas participan en la producción de los cuerpos, de los procesos de salud-enfermedad, de las sexualidades. Pero también resulta un hecho político en tanto la medida que ejerce ruptura con el determinismo identificando aquellos espacios desde los que es posible transformar lo social, lo institucional que conlleva desiguales modos de resolución de sus experiencias. Entonces, aunque sin estar en el guión, en esta escena se pone en evidencia el papel político también del campo educativo. La docente le dice al estudiante: "Tener educación te posibilita ver de otra manera las cosas".

En la reacción de $E$, y en las argumentaciones que se van tejiendo en la clase, también se puede destacar otro elemento, el lugar de los sujetos en la transformación de sus experiencias. Por un lado, el enojo de E potencia la posibilidad de visibilizarse como indignado por las injusticias sociales, y a partir de allí poder pensar las grietas, los lugares de transformación. Pero, anudado a esta situación, se identifica el lugar de los movimientos de mujeres. Cuando la profesora pregunta por qué el caso sale a la luz, se identifica la acción de los movimientos sociales en la construcción de la agenda pública, en la posibilidad de luchar contra las injusticias.

\section{Las emociones entran en escena, una dimensión pocas veces explorada}

Tal como menciona Eduardo MenendezMenéndez cuando se refiere al Modelo Médico Hegemónic $(\mathrm{MMH})$, una de sus características es la supremacía que se impone desde este modelo del Cconocimiento Ccientífico-Mmédico como único saber válido. La jerarquía binaria que establece una dicotomía valorativa entre saber cientificocientífico y prenociones/experiencias ha sido fuertemente discurtida por el feminismo, los estudios de género y la perspectiva crítica. Lejos de entender los sentidos, sentimientos, saberes, creencias como obstáculos en la construcción de conocimientos y prácticas sociales válidas, estos componentes se comprendenr como parte constitutiva de lo social que requiere entrar a escena para la consolidación de prácticas pedagógicas más eficaces. Durante la clase a la que remitimos, todos/das/dxs, varones, mujeres, docente, alumnoxs, observadoresx tienen algo que decir que merece ser escuchado. Cada uno de elloxs pone sobre la mesa sus saberes que tensionan, interrogan, reconfiguran los contenidos que circulan por el espacio.

En este punto, nos interesa detenernos especialmente en las emociones, el lugar que ellas tienen en las formas que toman las experiencias, en los modos que perfilan a los espacios educativos. Resulta significativa una escena en la cual se pone el acento respecto de las emociones que la llevan a Maríia Ovando a tener temores en el juicio oral y le impiden asistir a la sesión. Esas emociones se vinculan con la historia de Maríia, con su analfabetismo. En la clase hay silencio, todoxs escuchan las reflexiones de la docente, quien también aporta su experiencia personal, su emoción.

\section{Escena 4:}

$P$ : En la primera audiencia a María la tuvieron que suspender porque le dio mucho miedo, ¿miedo por qué?

Ao: pPorque vio muchos hombres con traje y carteles que ella no sabía qué decían y mucha gente gritando...

$P$ : aA veces es difícil la situación, nos largan en un lugar desconocido, a veces es difícil de comprender esas situaciones cuando uno no lo atravesó. Cuando empecé a trabajar como docente vivía en Jujuy con una señora mayor. Yo tuve con ella un vínculo muy particular, me cuidaba muy especialmente, cuando yo me volví de Jujuy lloraba. Cuando me fui, yo le escribía 
cartas y su nieta se las leía y ella me contestaba dictándole la carta a la nieta. La última carta que recibí de ella... ([P se emociona... llora... detiene el relato.) "no te preocupes", (le dice a alguien en tono tranquilizador]). Lo que pasa es que la historia es maravillosa... ella me dice que no me va a escribir más porque a ella le gustaba cuando hablábamos solas y nos quedábamos horas y horas charlando... y que eso le gustaba de charlar conmigo. Porque era de dos y no de 3. Se me cruzó cuando decíamos lo de analfabeto... que le podía pasar a María...

En este fragmento se ponen en escena diferentes situaciones de lo que para nosotras implica una pedagogía de la educación sexual desde la perspectiva de género. En primer lugar, da cuenta de cómo el analfabetismo conlleva una experiencia particular en la cual se presentan temores y otras emociones que impactan en las experiencias. La docente a través de su relato invita a ponerse en el lugar de un otro/a, a poder pensar qué le pasará, qué sentirá una persona que está atravesando una situación desconocida para mí. De alguna manera, aquí entra claramente en juego un eje de la educación sexual: la posibilidad de ponerse en lugar de otrx, comprender lo que le pasa/lo que siente.

Pero también la escena ilumina otro aspecto. Por un lado entra la emotividad, pero la emotividad de la docente. La emotividad que le genera la recuperación de una experiencia personal. La clase no se detiene, la docente sin dejar su lugar docente puede jugar en la escena como un sujeto social, con una experiencia, con emociones dispuestas a ser compartidas.

Para cerrar este apartado podemos decir que el trabajo con el caso mencionado, como así también la lectura crítica de datos estadísticos, de campañas de prevención, entre otros, potenciaron, tal como señaló M, "abrir preguntas donde había certezas". Esta experiencia no soólo propició esta apertura en loxs alumnxs con quienes se problematizó la experiencia de salud, sino que desestabilizó el mismo dispositivo pedagógico. Llevó a replantearnos el lugar docente; a enfrentar junto a $\mathrm{M}$ los temores que provoca la innovación en las prácticas; los límites, posibilidades y cuidados a tener en cuenta al trabajar estas temáticas y desde esta perspectiva; como así también revisar elementos centrales y constitutivos del dispositivo escolar, como por ejemplo la evaluación: ¿Qué se torna enseñable y qué se torna evaluable cuando se genera una propuesta curricular de EPS desde la perspectiva de género?

\section{Conclusiones}

En las instituciones educativas, la reflexión sobre el lugar de los cuerpos, sobre las identidades de género, y las prácticas y deseos sexo-afectivos, estuvo durante décadas fuera del universo de "lo pensable" y mucho menos de "lo enseñable". Incorporar una perspectiva de género a la vida institucional y al currículo requiere, en primer lugar, un proceso de desnaturalización del sistema sexo-género hegemónico por parte de la comunidad educativa, tanto a nivel institucional como individual, y esa reflexión demanda un tiempo significativo. Pero, a su vez, ese proceso de desnaturalización, en la medida en que es profundizado, exige enfrentarse con (lo que aquí llamamos) los "núcleos duros" del discurso patriarcal; discurso que permea todos los ámbitos de la vida social, y particularmente el escolar.

Las normativas como la ESI, y los avances en materia de leyes y consensos sociales sobre la ampliación de derechos en materia de género que se dieron en los últimos años en Argentina, contribuyen sin duda a desvelar las injusticas históricamente sufridas por estos grupos. Sin embargo, consideramos que es necesario hacer un análisis que distinga entre aquellos discursos que se limitan a aceptar a "lo otro diverso" como paradigma de la igualdad de aquellos que dan cuenta de la persistencia de una matriz epistémica que produce y valida la clasificación y jerarquización de los cuerpos, las identidades y los deseos. Este trabajo aspiró a complejizar esta segunda mirada, que requiere de una mayor introspección y análisis sobre las formas en que todoxs somos interpeladoxs por dicha matriz.

Esta matriz se encuentra entramada por sentidos que -actualizados, metamorfoseados o conservados-- configuran una serie de "núcleos duros", que en su reiteración producen y validan el sistema sexo-género hegemónico. El determinismo biológico constituye uno de esos "núcleos duros". Bajo un discurso pretendidamente neutral amparado en la racionalidad científica, esta conceptualización opera una "violencia epistémica" (Da Cunha, 2015) que sustenta al orden social injusto patriarcal y heterosexual. Este papel determinante de lo biológico se enlaza a una conceptualización androcéntrica de la ciencia y al esencialismo presente en los modos hegemónicos de caracterizar las formas de habitar los cuerpos, las identidades de género y las sexualidades.

El "modelo biomédico hegemónico" legitima y pone en práctica estos "núcleos duros", clasificando los cuerpos en un continuo de mayor o menor distancia a aquel orden natural. Las intervenciones a personas intersex, la persistente medicalización de los procesos reproductivos 
de las mujeres, la patologización y estigmatización de personas trans ( $y$ hasta hace no mucho, de gaiys y lesbianas) son algunas muestras de ello. La Nnaturaleza, desde esta mirada hegemónica, es entendida como garante del orden moral universal y sigue siendo utilizada para justificar las violencias patriarcales y homofóbicas, entre muchas otras.

Por último, concluimos que la perspectiva de género requiere un cierto nivel de audacia para experimentar la incertidumbre en el aula. En muchos casos son loxs jóvenes estudiantes quienes permanentemente tensionan los límites de los pensable y lo enseñable. Seguramente, sobre aquello que la escuela no se anima o no quiere hablar, los alumnos y las alumnas tengan mucho por decir. Aquello que se ignora, que se omite, que se deja afuera pone muchas veces en juego los límites de los propios conocimientos. Y pensando en las instituciones educati- vas, arriesgar lo obvio (Britzman, 1999), posicionarse en la curiosidad, en la incomodidad de no sentirse nunca tranquilo/a/ $x$ con lo que se piensa o lo que se omite, ataca a uno de los núcleos duros del oficio docente, de las lógicas institucionales y las relaciones de poder en las escuelas. Ir por lo que se ignora, por lo que se cuela entre las paredes de las escuelas, implica desafiar los límites de lo instituido, subvertir no soólo las categorías de pensamiento, sino también animarse a desafiar aquello que señala quién tiene cierto saber, y, por ende, el poder, desafiar lo institucional (Fainsod, 2013). Transversalizar la educación sexual implica repensar las relaciones de poder, los procesos de clasificación. La inclusión de temáticas de la sexualidad en la escuela es un derecho, pero también una posibilidad,. Uuna posibilidad de replantearnos a treinta años de democracia en Argentina, de qué hablamos cuando pensamos en una sociedad y en una escuela más igualitaria y más justa.

\section{Referencias}

Anderson, E. (2010). "Feminist Eepistemology and Pphilosophy of Sscience" [Epistemología feminista e historia de la Ciencia]. iEn E.dward N. Zalta (ed.),. The Sstanford Eencyclopedia of Pphilosophy. Edward N. Zalta (ed.). New York: Springer.

Bernstein, B. (1990). Poder, educación y conciencia. Barcelona: El Roure Ed.

Britzman, D. (1999). "Curiosidade, sexualidade e curriculo." eEn G. Lopes Louro, Guacira. O corpo educado. Pedagogias da sexualidade. Belo Horizonte: Autentica.

Castorina, J. A. (Agosto, 2004). "Naturalismo, culturalismo y significación social en la psicología del desarrollo". En: Cuadernos de Pedagogía, N ${ }^{a} 12$.Año VII7(12). Agosto 2004. Rosario, pp. 11 -266.

Connell, R. (1997). Escuela y justicia social. Madrid: Morata.

Da Cunha, M. (2015). "El currículum como Sspeculum." eEn A. M. Bach, AM (Ccoord.), Para una didáctica con perspectiva de género. Buenos Aires: UNSAM Edita.

Díaz Villa, G. (2012). Una pedagogía para la ESI. Cuadernos de Educación, . Universidad Nacional de Córdoba. Año X- N¹0(10).

Eliías, N. (1990). Compromiso y distanciamiento en Compromiso y distanciamiento. Barcelona: Península.
Fainsod, P. (Diciembre, 2013). "Democratizar incluso lo invisibilizado." en Revista El Monitor. Ministerio de Educación. Diciembre 2013.

Fernández, A. M. (2012). Lógicas sexuales: amor, política y violencias. Buenos Aires: Nueva Visión.

Glaser, B. S., y\& Strauss, A. (1967/1971). A. 1967 The discovery of grounded theory. New york: Aldine.

Maffía, D. (2007). "Epistemología feminista: la subversión semiótica de las mujeres en la ciencia.", en Revista Venezolana de Estudios de la Mujer, № 28. "Filosofía Feminista"

Menéndez, E. (1990). Morir de alcohol. Saber y hegemonía médica. México:,D.F. Consejo Nacional para la Cultura y las Artes.

Morgade, G. (2006). "Sexualidad y prevención: discursos sexistas y heteronormativos en la escuela media". En: Revista del Instituto de Investigaciones en Ciencias de la Educación. Facultad de Filosofía y Letras,. Universidad de Buenos Aires. Num. 24, 27-33.

Morgade, G. (Comp.) (2011). Toda educación es sexual. Buenos Aires:. La Crujía Ediciones.

Morgade, G. (2013). Notas epistemológicas desde una investigación feminista sobre educación sexual. Revista da FAEEBA-Educação e Contemporaneidade, 22(40). 
Pacheco Ladrón de Guevara, L. (2010). El sexo de la ciencia. México: Universidad Autónoma de Nayarit.

Rockwell, E. (2007). La experiencia etnográfica: historia y cultura en los procesos educativos. Buenos Aires: Paidós.

Schneck, A. (2009). Biología.: Darwin y la evolución. Aportes para la enseñanza nivel medio (1. ${ }^{a} \mathrm{Ed}$.). Buenos Aires: Ministerio de eEducación,-Gobierno de la Cciudad de Buenos aires. Aportes para la enseñanza Nivel medio. 1er Ed.
Sirvent, M. T., Lomagno, C., y LLosa, S. (2009). Intervención Ccomunitaria en contextos de pobreza en la Cciudad de Buenos Aires desde una perspectiva de Aanimación Ssociocultural e linvestigación- Aacción Pparticipativa. IV Coloquio Internacional en Animación. Universidad del Quebec en Montreal UQAM/Red Internacional de Animación RIA, 28-30.

Strauss, A., y Corbin, J. (2002). Bases de la investigación cualitativa. Técnicas y procedimientos para desarrollar teoría fundamentada. Medellín: Universidad de Antioquia. 